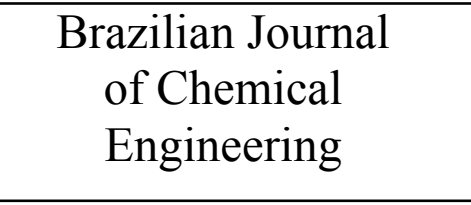

ISSN 0104-6632

Printed in Brazil www.abeq.org.br/bjche

Vol. 24, No. 03, pp. 433 - 443, July - September, 2007

\title{
REAL-TIME PROCESS OPTIMIZATION BASED ON GREY-BOX NEURAL MODELS
}

\author{
F. A. Cubillos ${ }^{1 *}$ G. Acuña ${ }^{2}$ and E.L. Lima ${ }^{3}$ \\ ${ }^{1}$ Depto. Ing. Química, ${ }^{2}$ Depto. Ing. Informática, Universidad de Santiago de Chile, \\ Fax: 56-2-6817135, Casilla 10233, Santiago, Chile. \\ E-mail: fcubillo@lauca.usach.cl \\ ${ }^{2}$ Programa de Engenharia Química, COPPE, Universidade Federal do Rio de Janeiro, \\ C.P.68502 CEP 21945-970, Rio de Janeiro - RJ, Brasil.
}

(Received: March 3, 2005 ; Accepted: March 13, 2007)

\begin{abstract}
This paper investigates the feasibility of using grey-box neural models (GNM) in Real Time Optimization (RTO). These models are based on a suitable combination of fundamental conservation laws and neural networks, being used in at least two different ways: to complement available phenomenological knowledge with empirical information, or to reduce dimensionality of complex rigorous physical models. We have observed that the benefits of using these simple adaptable models are counteracted by some difficulties associated with the solution of the optimization problem. Nonlinear Programming (NLP) algorithms failed in finding the global optimum due to the fact that neural networks can introduce multimodal objective functions. One alternative considered to solve this problem was the use of some kind of evolutionary algorithms, like Genetic Algorithms (GA). Although these algorithms produced better results in terms of finding the appropriate region, they took long periods of time to reach the global optimum. It was found that a combination of genetic and nonlinear programming algorithms can be use to fast obtain the optimum solution. The proposed approach was applied to the Williams-Otto reactor, considering three different GNM models of increasing complexity. Results demonstrated that the use of GNM models and mixed GA/NLP optimization algorithms is a promissory approach for solving dynamic RTO problems.

Keywords: Grey-box neural models; Real Time Optimization ; Genetic Algorithms.
\end{abstract}

\section{INTRODUCTION}

In the middle seventies various papers that changed the classical perception about the industrial process control were published in the scientific literature, most of them originated from industry. These works analyzed some relevant industrial process characteristics, discussing real necessities in terms of automatic control (Barkelew, 1976, Ellingsen, 1976, Latour, 1976, Lee and Weekman, 1976).
One of the most important process characteristics that the authors pointed out was the effect of non stationary external perturbations on the optimal operating point of the process. It was realized that in most cases the optimum is close to the intersection of constraint boundaries, which change under the effect of non-stationary perturbations (varying market conditions, changing raw materials, different product specifications, and the like), resulting in a dynamic environment. Such instabilities require a continuous tracking of an itinerant operating point.

*To whom correspondence should be addressed 
The immediate consequence of these publications was the interest from academy (and industry) in searching for strategies that could be efficiently used to follow the optimum. The problem is of such a huge complexity that during the last thirty years it has been receiving increasing attention, and represents an area of intensive and permanent research (Marlin and Hrymak, 1997, Zanin et. al., 2000).

The process of tracking the best operating point has been known by different names as for example: optimizing control (Arkun and Stephanopoulos, 1980), on-line optimization (White, 1997) and real time optimization (RTO). Today it seems to be an agreement on RTO (Yip and Marlin, 2004).

Three consecutive tasks must be executed during RTO:

- assessment of current plant operation status

- search for the new optimum

- implementation of results

Each of these tasks involves many complex and not totally well established activities.

Plant status assessment requires process variable measurements, which involves for instance, availability of reliable physical sensors (Bagajewicz, 2000), development of virtual sensors (Tham et al., 1989) if necessary, definition of sample times, pretreatment of data, fault detection (Venkatasubramanian et al., 2004) and data reconciliation (Romagnoli and Sánchez, 2000). Searching for the new operating point involves the solution of an optimization problem, which requires a clear definition of the objective function, constraints and the method of solution. Four different approaches have been used (Bhattacharya and Joseph, 1982): perturbation methods, direct methods, indirect methods, and dynamic model methods. Finally the implementation task involves a careful analysis of the optimization results, which may not represent a real option, due to errors from different sources (Marlin and Hrymak, 1997). After deciding the implementation of the new optimum, it is necessary to choose an efficient way to take the process from the original to the new operating point, which involves advanced techniques like model predictive control (Qin and Badgwell, 2003).

The complexity, uncertainty and, mainly, the magnitude of chemical plant processes represent important factors for RTO research be in an enthusiastic and permanent stage of development. The driving force of this enthusiasm is the significant return of investment associated to well succeed RTO (White, 1998; Nath and Alzein, 2000).

The RTO systems reduce the plant/model mismatch by updating the model with actual and historical plant data sets (Yip and Marlin, 2002). The performance of an RTO system is measured by the expected profit achieved, which is strongly influenced by the quality of the model used (Loeblein and Perkins, 1998, 1999). Since the early beginning it becomes clear that the non stationary behavior of chemical process operations require an RTO based on dynamic models (Bamberger and Isermann, 1978). Because the RTO execution is time consuming, simple phenomenological adaptable steady state models are currently used. In practical situations, however, it is difficult to reach the steady state among each RTO execution period, leaving the plant in a permanent state of slow dynamic changes. The problem is that the adaptation procedure requires the plant to be stationary, a very unreal situation in industrial plants (Bamberger and Isermann, 1978).

Under this condition model is not entirely consistent and an inefficient update process could reduce the economic performance of the plant. The key to solve this problem is the use of phenomenological dynamic plant models, which have the disadvantages of being difficult to obtain and update in real time. Various proposals have been suggested to reduce these problems (Sequeira et al., 2004, Yip and Marlin, 2004), but there is still plenty of room for new alternatives. Biegler et al. (2002) present a complete study about the simultaneous solutions of the dynamic RTO based on DAE models. These authors improve the optimization solver adding a novel filter in the line search and preconditioning the conjugated gradient. Also, the problem of moving finite elements was addresses trough an algorithms that adjust elements to track the optimal movements.

In this work we have investigated the feasibility of using grey-box neural models (GNM) in RTO. These models are based on a suitable combination of fundamental conservation laws and neural networks (NNs), and can be used in at least two different ways: to complement available phenomenological knowledge with empirical information, or to reduce dimensionality of complex rigorous physical models (Van can et. al., 1996). The benefits of using these simple adaptable models are counteracted by some difficulties associated with the solution of the optimization problem. Nonlinear Programming 
(NLP) algorithms failed in finding the global optimum due to the fact that neural networks can introduce multimodal objective functions. One alternative considered to solve this problem was the use of some kind of evolutionary algorithms, like Genetic Algorithms (GA). Although these algorithms produced better results in terms of finding the appropriate region, they took long periods of time to reach the global optimum. It was found that a combination of genetic and nonlinear programming algorithms can be use to fast obtain the optimum solution. The proposed approach was applied to the Williams-Otto reactor, considering three different GNM models of increasing complexity.

In this paper we considered that the introduction of multimodal objective functions due to the $\mathrm{NN}$ in the GNM is less disadvantageous than maintaining the complex first principles model in the RTO formulation because robust global optimization algorithms that allow fast solutions are easily available. Instead, solutions for complex models have more convergence problems.

The paper is organized as follows. In Section 2, the RTO problem, the GNM paradigm and the OttoWilliams reactor are summarized. Section 3 illustrates and discusses the implementation of
RTO with different GNM models and optimization algorithms. Finally, the paper is concluded in Section 4

\section{PROBLEM DESCRIPTION}

\section{RTO Structure}

A typical RTO system, as shown in Figure 1, includes the following elements: model updater, modelbased optimizer, result analysis and process control.

Real-time measurements are made for plant status assessment and used for model parameter estimation. The updated model is used by the optimizer to find the optimum operating point. This information is analyzed and, if approved, transmitted to the process controllers. Only significant changes in optimization variables are forwarded to the process controllers for implementation. Naturally, design decisions strongly affect the closed-loop RTO performance. Design procedures have been developed to select an appropriate model for RTO system (Forbes et al., 1994). Parameters for updating are selected by minimizing the offset and variability (Forbes and Marlin, 1996).

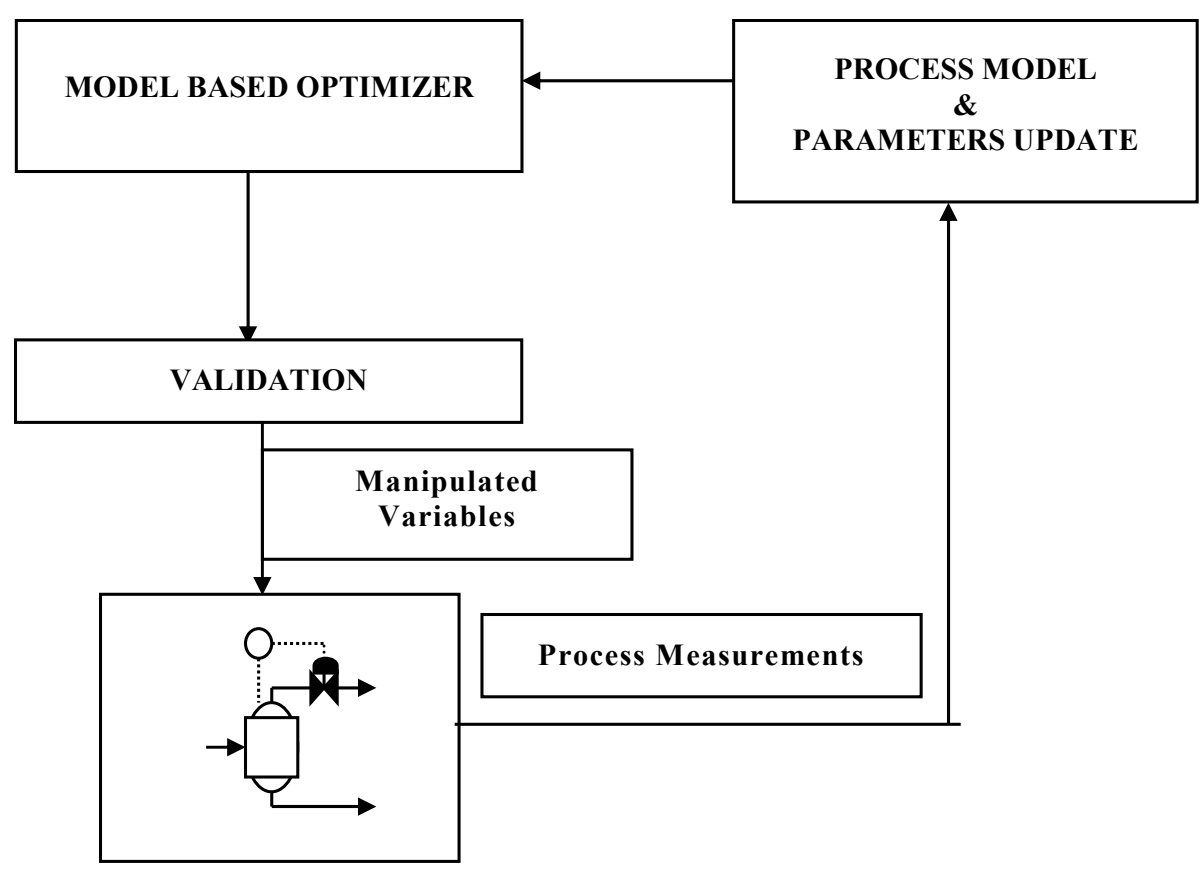

Figure 1: The RTO loop 


\section{RTO Formulation}

The optimum operating policy is determined based on the updated model and an economic objective function. In this work, only material and energy balances, which are equality_constraints, are considered in the model. The economic optimization problem that must be solved for RTO can be stated as

$\max P(x, \beta)$

s. t. $\begin{aligned} & f(x, \beta)=0 ; \\ & x \geq 0\end{aligned}$

where $\mathrm{P}$ is the economic objective function, $\mathbf{f}$ is a vector representing the process model, $\boldsymbol{\beta}$ is a vector of the parameters to be estimated for process model updating, and $\mathbf{x}$ is a vector of the optimization variables, including dependent and independent variables.

\section{GNM Model}

Grey-box Neural Models combine a phenomenological model of the system with neural networks and enable the synthesis of simpler mathematical models than purely phenomenological ones, with more robust generalization properties than purely black-box neural models. These two properties make the GNM especially attractive in tasks associated with Process Identification, Process Control and Optimization, (Cubillos and Lima, 1998; Xiong and Jutan, 2002) .

The GNM approach consists of the formulation of a process model by equations derived from phenomenological principles - such as mass, energy and momentum balances - and neural networks, which estimate uncertain parameters or the ones difficult to model. Such approach represents an attempt to add prior knowledge to black-box neural models, in order to reduce their complexity and improve their adaptive and predictive properties (Psichogios and Ungar, 1992). Thompson and Kramer (1994) classified these grey-box models into two main types: models with the $\mathrm{NN}$ bringing intermediate values (parameters or variables) to be used in the phenomenological model (series greybox models) or models with the NN in parallel with the dynamic model compensating the plant/model mismatch (parallel grey-box models). Figure 2 shows the series scheme for a grey-box model as used in this work.

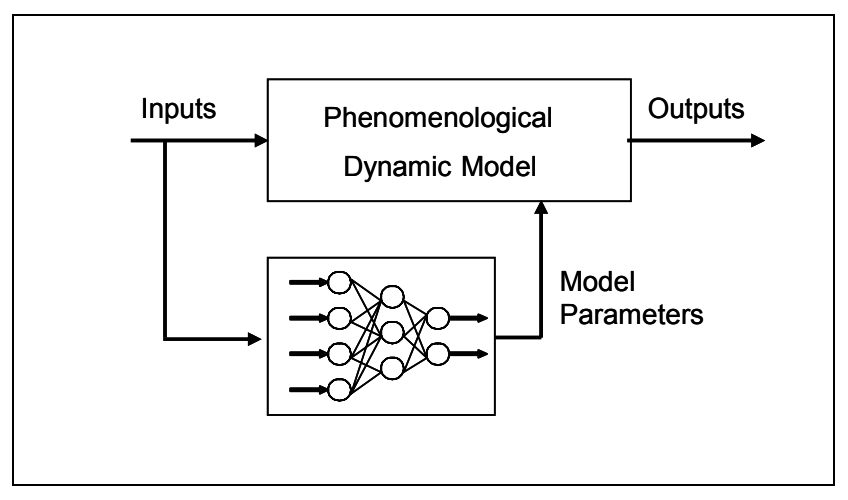

Figure 2: The GNM approach

\section{Otto-Williams Reactor}

The proposed approach was applied to the simulated continuous system tank reactor (CSTR) from the Otto-Williams benchmark plant modified by Forbes and Marlin (1996), as illustrated in Figure 3.

The following reactions are conducted in the reactor:

$$
\mathrm{A}+\mathrm{B} \rightarrow \mathrm{C} \quad \mathrm{k}_{1}=\mathrm{k}_{01} \mathrm{e}^{-\frac{\mathrm{B}_{1}}{\mathrm{~T}_{\mathrm{r}}}}
$$

$$
\begin{array}{ll}
\mathrm{C}+\mathrm{B} \rightarrow \mathrm{P}+\mathrm{E} & \mathrm{k}_{2}=\mathrm{k}_{02} \mathrm{e}^{-\frac{\mathrm{B}_{2}}{\mathrm{~T}_{\mathrm{r}}}} \\
\mathrm{P}+\mathrm{C} \rightarrow \mathrm{G} & \mathrm{k}_{3}=\mathrm{k}_{03} \mathrm{e}^{-\frac{\mathrm{B}_{3}}{\mathrm{~T}_{\mathrm{r}}}}
\end{array}
$$

Assuming an ideal CSTR with no reactor temperature dynamics, the model equations for each species are given by:

$\mathrm{V}_{\mathrm{r}} \frac{\mathrm{dx} \mathrm{a}_{\mathrm{a}}}{\mathrm{dt}}=\mathrm{F}_{\mathrm{a}}-\left(\mathrm{F}_{\mathrm{a}}+\mathrm{F}_{\mathrm{b}}\right) \mathrm{x}_{\mathrm{a}}-\mathrm{V}_{\mathrm{r}} \mathrm{x}_{\mathrm{a}} \mathrm{x}_{\mathrm{b}} \mathrm{k}_{01} \mathrm{e}^{-\mathrm{B}_{1} / \mathrm{T}_{\mathrm{r}}}$ 
$\mathrm{V}_{\mathrm{r}} \frac{\mathrm{dx}_{\mathrm{b}}}{\mathrm{dt}}=\mathrm{F}_{\mathrm{b}}-\left(\mathrm{F}_{\mathrm{a}}+\mathrm{F}_{\mathrm{b}}\right) \mathrm{x}_{\mathrm{b}}-$

$\mathrm{V}_{\mathrm{r}}\left(\mathrm{x}_{\mathrm{a}} \mathrm{x}_{\mathrm{b}} \mathrm{k}_{01} \mathrm{xe}^{-\mathrm{B}_{1} / \mathrm{T}_{\mathrm{r}}}+\mathrm{x}_{\mathrm{b}} \mathrm{x}_{\mathrm{c}} \mathrm{k}_{02} \mathrm{e}^{-\mathrm{B}_{2} / \mathrm{T}_{\mathrm{r}}}\right)$

$\mathrm{V}_{\mathrm{r}} \frac{\mathrm{dx}_{\mathrm{c}}}{\mathrm{dt}}=-\left(\mathrm{F}_{\mathrm{a}}+\mathrm{F}_{\mathrm{b}}\right) \mathrm{x}_{\mathrm{c}}+\mathrm{V}_{\mathrm{r}}\left(2 \mathrm{x}_{\mathrm{a}} \mathrm{x}_{\mathrm{b}} \mathrm{k}_{01} \mathrm{e}^{-\mathrm{B}_{1} / \mathrm{T}_{\mathrm{r}}}-\right.$

$\left.2 x_{b} x_{c} k_{02} e^{-B_{2} / T_{r}}-x_{c} x_{p} k_{03} e^{-B_{3} / T_{r}}\right)$

$\mathrm{V}_{\mathrm{r}} \frac{\mathrm{dx}}{\mathrm{dt}}=-\left(\mathrm{F}_{\mathrm{a}}+\mathrm{F}_{\mathrm{b}}\right) \mathrm{x}_{\mathrm{e}}+2 \mathrm{~V}_{\mathrm{r}} \mathrm{x}_{\mathrm{b}} \mathrm{x}_{\mathrm{c}} \mathrm{k}_{02} \mathrm{e}^{-\mathrm{B}_{2} / \mathrm{T}_{\mathrm{r}}}$

$$
\begin{aligned}
& \mathrm{V}_{\mathrm{r}} \frac{\mathrm{dx} \mathrm{p}_{\mathrm{p}}}{\mathrm{dt}}=-\left(\mathrm{F}_{\mathrm{a}}+\mathrm{F}_{\mathrm{b}}\right) \mathrm{x}_{\mathrm{p}}+ \\
& \mathrm{V}_{\mathrm{r}}\left(\mathrm{x}_{\mathrm{b}} \mathrm{x}_{\mathrm{c}} \mathrm{k}_{02} \mathrm{e}^{-\mathrm{B}_{2} / \mathrm{T}_{\mathrm{r}}}-0.5 \mathrm{x}_{\mathrm{p}} \mathrm{x}_{\mathrm{c}} \mathrm{k}_{03} \mathrm{e}^{-\mathrm{B}_{3} / \mathrm{T}_{\mathrm{r}}}\right) \\
& \mathrm{V}_{\mathrm{r}} \frac{\mathrm{dx} \mathrm{g}}{\mathrm{dt}}=-\left(\mathrm{F}_{\mathrm{a}}+\mathrm{F}_{\mathrm{b}}\right) \mathrm{x}_{\mathrm{g}}+1.5 \mathrm{~V}_{\mathrm{r}} \mathrm{x}_{\mathrm{p}} \mathrm{x}_{\mathrm{c}} \mathrm{k}_{03} \mathrm{e}^{-\mathrm{B}_{3} / \mathrm{T}_{\mathrm{r}}}
\end{aligned}
$$

In these equations $\mathrm{F}_{\mathrm{i}}$ are the species mass flow rates, $\mathrm{x}_{\mathrm{i}}$ are the species mass fractions, $\mathrm{V}_{\mathrm{r}}$ is the reactor mass hold-up and $T_{r}$ is the reactor temperature. The values of the kinetic parameters $\mathrm{k}_{\mathrm{i}}, \mathrm{k}_{0 \mathrm{i}}$, and $\mathrm{B}_{\mathrm{i}}$ are given in Table 1 .

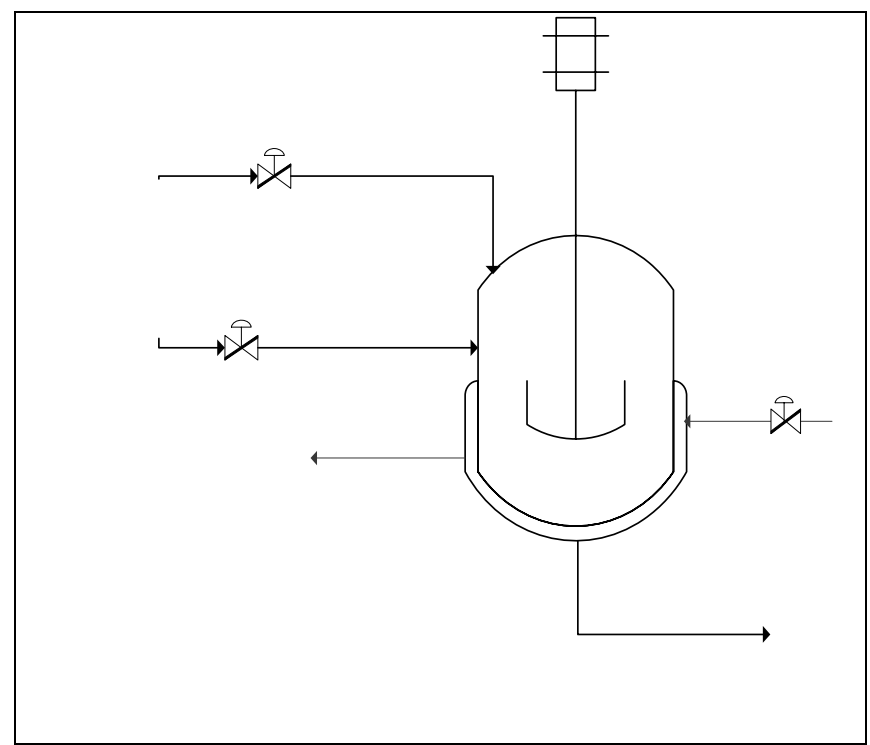

Figure 3: The Otto-Williams reactor

Table 1: Otto-William kinetic parameters

\begin{tabular}{|l|c|c|}
\hline & $\mathrm{k}_{01}=1.6599 \cdot 10^{6}$ & $\mathrm{~B}_{1}=6666.7^{\circ} \mathrm{K}$ \\
& $\mathrm{k}_{02}=7.2117 \cdot 10^{8}$ & $\mathrm{~B}_{2}=8333.3^{\circ} \mathrm{K}$ \\
& $\mathrm{k}_{03}=2.6745 \cdot 10^{12}$ & $\mathrm{~B}_{3}=11111^{\circ} \mathrm{K}$ \\
\hline
\end{tabular}

\section{GNM Synthesis}

To study the feasibility of the use of the GNM type models in RTO, three different modelling schemes were selected as described in Forbest et al. (1994):

i) Single reaction approximation (M1): $\mathrm{A}+2 \mathrm{~B} \rightarrow \mathrm{P}+\mathrm{E}$ ii) Two-reaction approximation (M2): $\mathrm{A}+2 \mathrm{~B} \rightarrow \mathrm{P}+\mathrm{E}$; $\mathrm{A}+\mathrm{B}+\mathrm{P} \rightarrow \mathrm{G}$

iii) Complete three-reaction system (M3) as described in (3).

Each GNM was synthesized considering the non stationary mass balance for each species. Feedforward neural networks were used to estimate 
the hypothetical reaction rates with unknown kinetic, $R_{j}$. Target values for these parameters were calculated directly from a discrete version of the mass balances. For example, for a single reaction model (M1), the reaction rate $R_{1}$ may be estimated using a discrete version of the $\mathrm{P}$ component balance, as follows

$$
\begin{aligned}
& \mathrm{R}_{1}(\mathrm{k})=\left[\left(\mathrm{F}_{\mathrm{a}}+\mathrm{F}_{\mathrm{b}}\right) \cdot \mathrm{x}_{\mathrm{p}} / \mathrm{V}_{\mathrm{r}}\right] \\
& (\mathrm{k})+\left(\mathrm{x}_{\mathrm{p}}(\mathrm{k})-\mathrm{x}_{\mathrm{p}}(\mathrm{k}-1)\right) / \Delta \mathrm{t}
\end{aligned}
$$

where $(\mathrm{k})$ denotes actual discrete time and $\Delta \mathrm{t}$ the time interval.

The decision variables of the optimization problem were chosen as the reactor temperature, $T_{r}$, and the flow rate of component $\mathrm{B}, \mathrm{F}_{\mathrm{b}}$. The flow rate of component $\mathrm{A}, \mathrm{F}_{\mathrm{a}}$, and reactor mass holdup, $\mathrm{V}_{\mathrm{r}}$, were fixed at $2 \mathrm{~kg} / \mathrm{s}$ and $2010 \mathrm{~kg}$, respectively. Under these conditions, the true optimum was calculated as $\mathrm{F}_{\mathrm{b}}=5.1869 \mathrm{~kg} / \mathrm{s}$ and $\mathrm{T}_{\mathrm{r}}=90.85{ }^{\circ} \mathrm{C}$; the corresponding instantaneous profit was $\mathrm{P}=198.45$ (\$) .
In order to obtain adequate data for the estimation of the reaction rates, pseudo random binary input sequences were used for $F_{b}$ and $T_{r}$, with a sample period of $1000 \mathrm{~s}$. Operating conditions and output concentrations were recorded to be used during the $\mathrm{NN}$ training procedure. Model updating, consisting of the $\mathrm{NN}$ adaptation, was carried out using a second order recursive optimization algorithm (Chen et al. 1990). The best NN structures were found by a systematic training procedure, considering the output concentrations of components $\mathrm{A}$ and $\mathrm{B}$, and the reactor temperature as input variables to the networks. Finally, networks with one hidden layer, four nodes and sigmoidal activation functions were selected.

A similar approach was used to derive the other GNM models, where the NNs were used to estimate the respective reaction rates with equal topology as used in the first approach. Figure 4 shows the prediction of the output concentration for E product using M2 model, with pseudo random binary perturbations on the input variables. Similar results were found for M1 and M3 models, showing that the GNM scheme is able to adequately track the process dynamics.

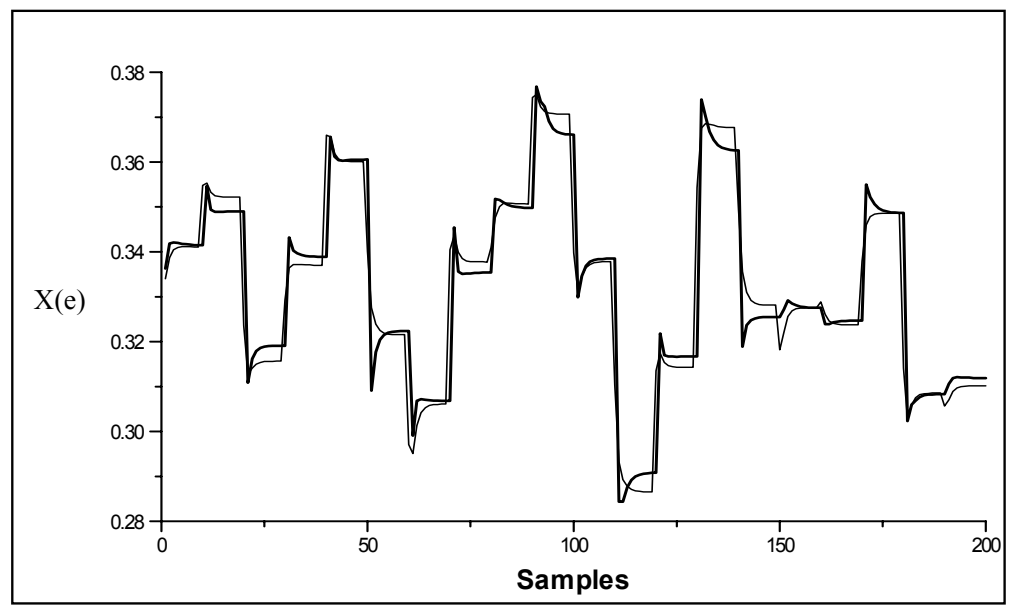

Figure 4: Actual (-) and GNM (-----) X(e) output concentration

\section{IMPLEMENTATION AND RESULTS}

Based on the updated dynamic GNM it was possible to derive an equivalent steady state model, able to be used in the RTO formulation. To illustrate the approach, considering the second approximation (M2), it is necessary to estimate two reaction rates $\left(\mathrm{R}_{1}\right.$ and $\mathrm{R}_{2}$ ) by means of neural networks. Steady state GNM model equations are M2:

$$
\begin{aligned}
& \mathrm{F}_{\mathrm{a}}-\left(\mathrm{F}_{\mathrm{a}}+\mathrm{F}_{\mathrm{b}}\right) \mathrm{x}_{\mathrm{a}}-\mathrm{R}_{1} \mathrm{~V}_{\mathrm{r}}-\mathrm{R}_{1} \mathrm{~V}_{\mathrm{r}}=0 \\
& \mathrm{~F}_{\mathrm{b}}-\left(\mathrm{F}_{\mathrm{a}}+\mathrm{F}_{\mathrm{b}}\right) \mathrm{x}_{\mathrm{b}}-2 \mathrm{R}_{1} \mathrm{~V}_{\mathrm{r}}-\mathrm{R}_{2} \mathrm{~V}_{\mathrm{r}}=0 \\
& -\left(\mathrm{F}_{\mathrm{a}}+\mathrm{F}_{\mathrm{b}}\right) \mathrm{x}_{\mathrm{p}}+\mathrm{R}_{1} \mathrm{~V}_{\mathrm{r}}-\mathrm{R}_{2} \mathrm{~V}_{\mathrm{r}}=0 \\
& -\left(\mathrm{F}_{\mathrm{a}}+\mathrm{F}_{\mathrm{b}}\right) \mathrm{x}_{\mathrm{e}}+2 \mathrm{R}_{1} \mathrm{~V}_{\mathrm{r}}=0 \\
& -\left(\mathrm{F}_{\mathrm{a}}+\mathrm{F}_{\mathrm{b}}\right) \mathrm{x}_{\mathrm{g}}+3 \mathrm{R}_{2} \mathrm{~V}_{\mathrm{r}}=0
\end{aligned}
$$


The complete model is composed by these five equations and two NNs to calculate R1 and R2. Decision variables $F_{b}$ and $T_{r}$ are explicit in the equations and implicit in the NNs inputs

$\left(\mathrm{x}_{\mathrm{a}}, \mathrm{x}_{\mathrm{b}}, \mathrm{T}_{\mathrm{r}}\right)$.

\section{NLP Strategy}

The GNM approach with the three alternative adaptive models were tested in the RTO scheme considering similar operating conditions as used by Forbes and Marlin (1996), with feed flow rate and reactor temperature as the optimization variables. The optimization objective is to maximize the profit, as indicated in Equation 4, constrained by the corresponding GNM models. At this stage, the NN parameters were kept constant. Additional bounds were incorporated in $F_{b}$ and $T_{r}$ in order to improve convergence properties. The optimization problem is given by:

$\operatorname{Min} \operatorname{Tr}, \mathrm{Fb}\left(-\mathrm{P}=1143.38^{*} \mathrm{Xp} * \mathrm{Fr}+25.92 *\right.$

$\mathrm{Xe} * \mathrm{Fr}-23 * \mathrm{Fa}-114.34 * \mathrm{Fb})$

s.t.

$\mathrm{M} 1, \mathrm{M} 2$, or $\mathrm{M} 3=0$

$0=\mathrm{F}_{\mathrm{b}}=10$

$0=\mathrm{T}_{\mathrm{r}}=150$
Concerning Figure 1, model update parameters were made off-line with the dynamical data base (Figure 4), instead the optimizer was linked on-line with the process. No validation procedures were considered.

A dynamic test was applied considering the reactor operating in a non optimum point. At a pre-established time, the RTO was connected to the plant, running each sample time in order to position the process at the optimum. Current reactor states were used as initial guess to the next optimization step. The optimization problem was solved using the SQP algorithm (Edgard and Himmelblau, 1988) included in the optimization toolbox of Matlab. Figure 5 shows the behavior of the RTO system for the three GNM models and the true (nominal) model over a time horizon of 4200s (21 RTO executions). Figure 6 shows the $\operatorname{Tr}$ movements, $\mathrm{Fb}$ is fixed in the optimum value $(\mathrm{Fb}=4.7 \mathrm{~kg} / \mathrm{s})$ at the first sample by the optimizer in all models.

Results indicate that all GNM models were able to find an optimal set of variables close to the true optimum and maintain these conditions over the time. It can be observed that deviations from the nominal optimum are as more severe as less exact is the process model used in the RTO. Other issue observed is the sensitiveness of the RTO/GNM system to the initial conditions in the optimizer. In order to compare the performances of the models considered in this work, a dynamic performance index, defined as the total profit obtained over the time window was calculated. It can be observed that results improve as the process/model mismatch is reduced as presented in Table 2

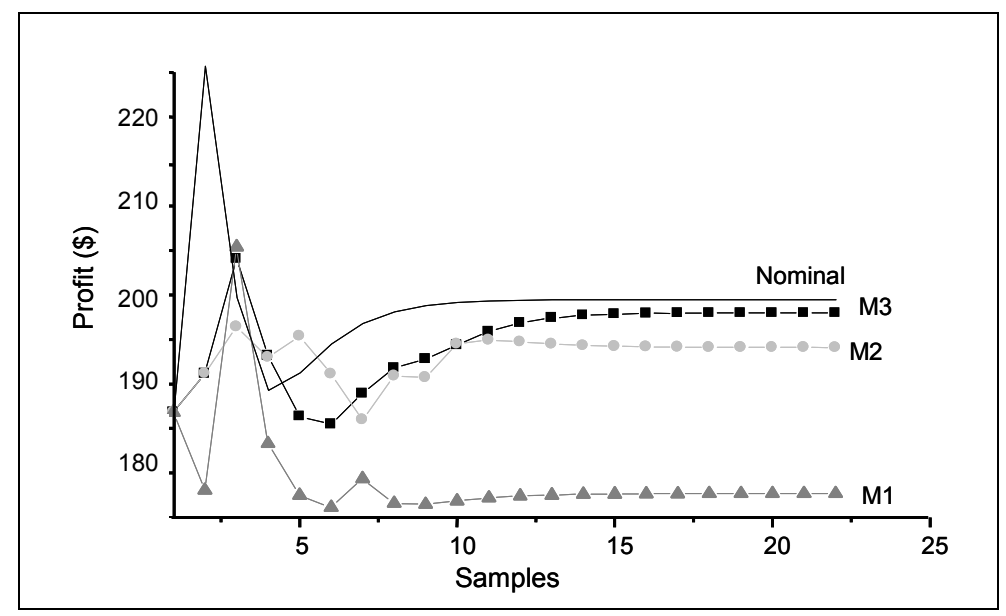

Figure 5: Instantaneous profit evolution

Table 2: Cumulative profit

\begin{tabular}{|l|c|c|c|c|}
\hline Model & True & GNM/M3 & GNM/M1 & GNM/M1 \\
\hline Cumulative Profit (\$) & 4362 & 4236 & 4205 & 3892 \\
\hline
\end{tabular}




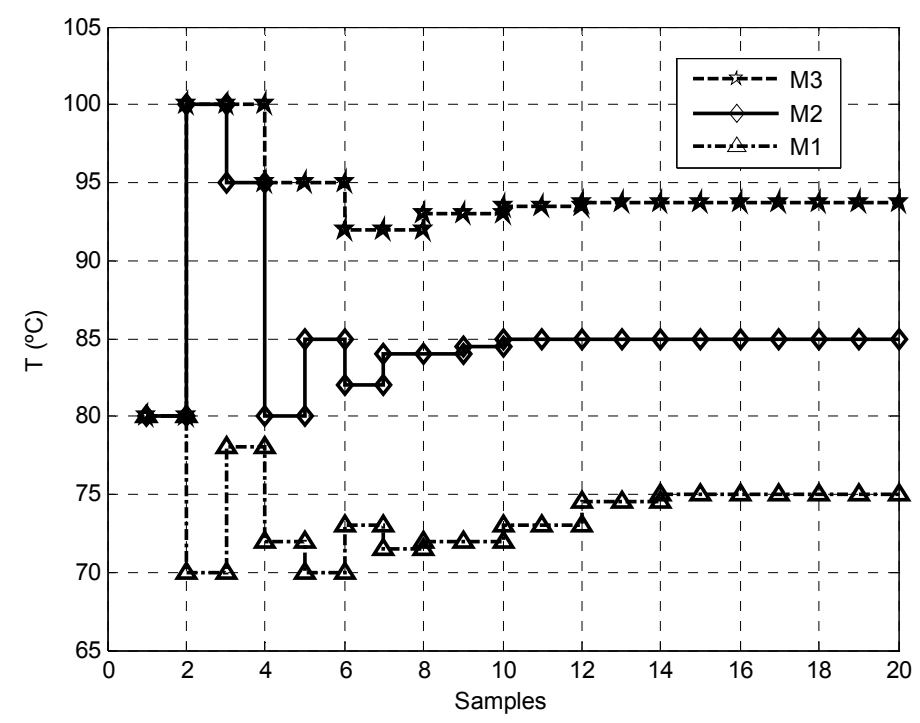

Figure 6: Manipulated variable Tr.

\section{Genetic Algorithm}

As mentioned above, it was observed that the performance of the NLP approach was very sensitive to the initial condition. Several tests were carried out in order to find the cause of this behaviour, and finally it was found that the NN training quality was the main factor. Most of the analyzed GNM models presented multimodal behaviour with local optimum values, mainly for less intensive trained NNs. To illustrate this behaviour Figure 6 shows the profit response surface after a long training cycle of the NN (10000 epochs). The presence of a local minimum is evident.

To cope with this problem, it was considered the use of a global optimization solver based on genetic algorithms.

Genetic algorithms are stochastic optimization methods based on the biological principles of natural selection (Goldberg, 1989). These methods are especially suitable for multimodal objective functions, often observed in models based on neural networks, as they are less probable to get trapped in local optima. In GA, the decision variables are encoded into bit strings and submitted to crossover and mutation mechanisms based on the evolutionary theory. The reproduction is determined by a fitness function associated with the capability of survival of an individual. The main characteristics of GA are: search from a population and evaluation of fitness (performance) function as a black box. The efficiency of a GA is closely linked with the objective function and set-up parameters as: encoded strings, bit resolution, initial population, number of generations, and operator probabilities. Experience indicates that due to the large number of GA parameters, a suitable set-up should be determined for each particular problem.

In order to evaluate the performance of the proposed approach, the previous dynamic test was applied. As the main objective of this work is to evaluate grey-box neural models in RTO, a simple GA with no special effort in parameter setting-up was used. Component B flow rate and reactor temperature were encoded in binary strings of 16 bits. A population size of 50 pairs of individuals was kept constant over the generations. A total of 30 generations was used to find the optimum.

The obtained results shown good agreement with the same problem solved by the NLP technique, getting the process near of the true optimum. The cumulative profit and an index of affectivity of each algorithm (i.e. \% to reach the true optimum) for the nominal and the M3 model RTO scheme, using both NLP and GA methods, are given in Table 3 .

A comparative analysis indicates that the GNMGA approach is more computers demanding than the GNM-NLP one, but is more stable as it does not depend on the initial guess. On the other hand, GNM-GA was not able to position the system in the true optimum. This is inherent to the GA formulation and it could be improved if an interval mixed GANLP optimization scheme is applied (ValdesGonzalez et al, 2003). 


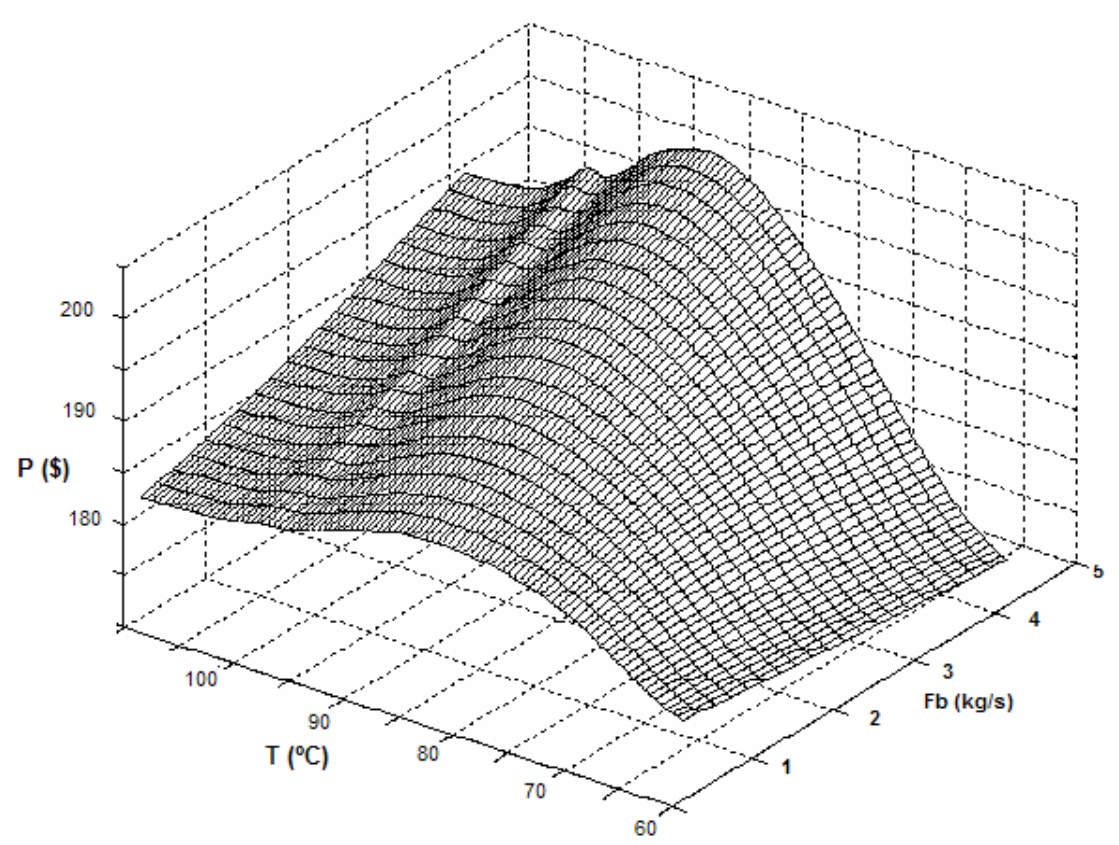

Figure 7: Response surface to profit with M3 Model.

Table 3: Cumulative profit (M3 model) and computing demand

\begin{tabular}{|l|c|c|c|c|}
\hline Scheme & True & GNM-NLP & GNM-GA & GA-NLP \\
\hline Cumulative Profit (\$) & 4362 & 4236 & 4218 & 4325 \\
\% reach optimum & - & 77 & 95 & 99 \\
Float operations p secons (flops) & & 3500 & 8900 & 10250 \\
\hline
\end{tabular}

\section{GA-NLP Approach}

Based on the previous results, a hybrid GA/NLP scheme was developed and tested to solve the RTO problem. In this scheme each execution starts with a short GA (50 data pair and 10 generations) to find the region that contains the global optimum. This G.A. setting was obtained in order to have an adequate compromise between speed and precision. Subsequently, a NLP algorithm, starting with a random point inside this region is used to find the optimum. The results with the GA/NLP scheme have shown an excellent performance. These results are better than the ones of the schemes previously analyzed in terms of algorithm stability and quality of the optimum obtained. The cumulative profit and the affectivity index values for the nominal and the M3 model RTO scheme, with NLP, GA and GA/NLP optimization algorithms, are given in Table 3. Tests carried out in a dynamic environment achieved $99 \%$ of effectiveness to find the optimum starting from several non optimum operational conditions. Obviously, the computational effort of this approach is bigger than the one required by each method separately, with about $50 \%$ increment of float point operations in each cycle of solution.

\section{CONCLUSIONS}

The ability of RTO systems to track the optimum operating point of a plant depends on the accuracy of model structure and model adaptability (efficient parameter estimation). In this work, different dynamic grey-box neural models for RTO are studied in order to reduce dimensionality and favor adaptability. From these models it is possible to obtain good information of the steady state characteristic of the plant, even if the steady state condition was not reached because the dynamic process data are used to fit a dynamical GNM model of the process and this GNM model is first principles consistent. Consequently, the model parameters (kinetics rates) may be used in an equivalent steady 
state model for the optimization step. The proposed models were successfully used for RTO of the OttoWilliams reactor.

The solution of the optimization problem by classical NLP techniques was possible, but not guaranteed, as the neural network in the GNM model may result in multimodal objective functions. To cope with this problem, a strategy based on GA was implemented. Such strategy guarantees reasonable convergence to the global optimum; however, the results were not as good as the ones obtained when NLP converges. Also, it requires a greater computational effort. Finally a hybrid GA-NLP was successfully applied to solve the problem with an efficient global optimum determination. The above mentioned approach may be used even in the presence of process disturbances if they are measured and considered as inputs in the GNM model.

The suggested approach introduces improvements in the RTO technology, allowing extension to highly nonlinear plants and a feasible on-line adaptation using dynamic information.

\section{ACKNOWLEDGMENTS}

Authors wish to acknowledge the collaboration of the Professor Jose Romagnoli by the valuable comments and suggestions in the final version of this work. Also, we appreciate the financial support provided by FONDECYT (Projects 1040208) and Dicyt-Usach, Grant 0611CM.

\section{NOMENCLATURE}

$\mathrm{B}_{\mathrm{j}} \quad$ activation parameter in reaction

f plant model

$\mathrm{k}$ discrete time

$\mathrm{F}_{\mathrm{i}} \quad$ flow rate of component

$\mathrm{k}_{\mathrm{j}} \quad$ kinetic constant in reaction

$\mathrm{k}_{0 \mathrm{j}} \quad$ frequency factor in reaction

$\mathrm{P} \quad$ economic objective function

$R_{j} \quad$ reaction rate in reaction

$\mathrm{t}$ : $\quad$ continuous time

$\Delta \mathrm{t} \quad$ sampling period

$\mathrm{T}_{\mathrm{r}} \quad$ reactor temperature

$\mathrm{V}_{\mathrm{r}} \quad$ mass reactor hold-up $\mathbf{x} \quad$ vector of process variables

$\mathbf{X}_{\mathrm{i}} \quad$ mass fraction of component

$\boldsymbol{\beta}$

vector of model parameters

\section{REFERENCES}

Arkun, Y, Stephanopoulos, G, 1980, Studies in the Synthesis of Control Structures for Chemical Processes, Par IV. Design of Steady-State Optimizing Control structures for Chemical Process Unit, AIChE J., 26(6), 975-991.

Bagajewicz, M., 2000, Process Plant Instrumentation: Design and Upgrade, CRC Press.

Bamberger, W., Isermann, R., 1978, Adaptive OnLine Steady-State Optimization of Slow Dynamic Processes, Automatica, 14, 223-230.

Barkelew, C. H., 1976, Modern Process ControlState of the Art in Petroleum Refining, AIChE Symp. Ser., 159, 72.

Bhattacharya, A., Joseph, B., 1982, On-line Optimization of Chemical Processes, Proc. ACC, 334-337.

Biegler L, Cervantes A, and Wachter A, 2002, "Advances in simultaneous strategies for dynamic process optimization", Chem,Eng:Sci, (57), 575,593.

Chen S. Cowan C. Billings S. and Grant P., 1990, "Parallel recursive prediction error algorithm for training layered neural networks," Int.J.Control,51,6.

Cubillos F. and Lima E., 1998, Adaptive hybrid neural models for process control, Computers and Chemical Engineering, Vol 22, S989-S992.

Edgard T. and Himmelblau D. "Optimization of Chemical Processes," McGraw Hill Book Co., New York,1988.

Ellingsen. W. R., 1976, Implementation of Advanced

Control systems, AIChE Symp. Ser., 159, 72.
i
Forbest F. Marlin T. and MacGregor J., 1994, Model Adequacy Requirements For Optimizing Plant Operations , Computers and Chemical Engineering, Vol 18, pp. 497-510.

Forbes, J. F. and Marlin, T. E.,1996, Design Cost: A Systematic Approach to Technology Selection for Model-Based Real-Time Optimization Systems. Computers and Chemical Engineering, Vol 20, 717-734.

Goldberg, D.,1989, "Genetic Algorithms in Search, Optimization and Machine Learning", AddisonWesley. 
Latour, P. R., 1976, Comments on Assessments and Needs, AIChE Symp. Ser., 159, 72.

Lee, W. Weekman Jr., W. V., 1976, Advanced Process Practice in the chemical Process Industry: A View from Industry, AIChE J., 22.

Loeblein C. and Perkins J, 1998, Economic analysis of different structures of on-line process optimization systems, Computers and Chemical Engineering, Vol. 22, pp.1257-1269.

Loeblein C. and Perkins J.,1999, "Structural Design for On-Line Process Optimization: I Dynamic Economics of MPC", AIChE J., Vol. 45, N 5

Marlin, T. E., Hrymak, A. N., 1997, Real-Time Operations Optimization of Continuous Processes, AIChE Symp. Ser., 316, 156-164.

Nath,R; and Alzein Z.,2000, On-line dynamic optimization of olefins plants, Computers and Chemical Engineering, Vol 24,533-5338.

Psichogios D. and Ungar L., 1992, A hybrid neural networks-first principles approach to process modeling, AIChE J.,38,1

Qin, S. J. and Badgwell, T. A., 2003, A survey of industrial model predictive control technology, Control Engineering Practice, 11, 733-764.

Romagnoli, J. A., Sánchez, M. C., 2000, Data Processing and Reconciliation for Chemical Process Operations, AP Process System Engineering, volume 2.

Sequeira, S.E. Herrera, M. Graells, M. Puigjaner, L.2004, On-line process optimization: parameter tuning for the real time evolution (RTE) approach, Computers and Chemical Engineering, Vol 28,5.

Tham, M. T., Morris, A. J., Montague, G. A., 1989, Soft-Sensing: A Solution to the Problem of Measurement Delays, Chem. Eng. Res. Dev., 67, 547-554.

Thompson M. and Kramer M., 1994, Modeling chemical processes using prior knowledge and neural networks, AIChE J.,40,132.

Valdés-González, H, Flaus J.M, and Acuña,G., 2003, "Moving Horizon State Estimation with Global Convergence Using Interval Techniques: Application to Biotechnological Processes", Journal of Process Control, Vol. 13/4, pp. 325336.

Van Can, HJL, Hellinga, C, Luyben, KAM and Heijnen, JJ , 1996, Strategy for Dynamic Process Modeling Based on Neural Networks in Macroscopic Balances, AIChE J. 42:3403-3418, (1996).

Venkatasubramanian, V., Rengaswamy, R., Yin, K., Kavuri, S., 2004, A Review of Process Fault Detection and Diagnosis. Part I: Quantitative Model-Based Methods, Chemical engineering Science, 56, 2133-2148.

White, D. C., 1997, Online optimization: what, where and estimating ROI, Hydrocarbon Processing, June, 43-51.

White, D. C., 1998, Online optimization: what have we learned?, Hydrocarbon Processing, June, 55-59.

Xiong Q. and Jutan A., 2002, Grey-box modelling and control of chemical processes, Chemical Engineering Science, Volume 57, 6, 1027-1039.

Yip, W. S. and Marlin, T. E., 2002, Multiple data sets for model updating in real-time operations optimization, Computers and Chemical Engineering, 26, 1345-1362.

Yip, W. S. and Marlin, T. E., 2004, The effect of model fidelity on real-time optimization performance, Computers and Chemical Engineering, 28, 267-280.

Zanin,A; Tvrzka de Gouvea,M and Odloak,D, 2000, Industrial implementation of a real-time optimization strategy for maximizing production of LPG in a FCC unit", Computers and Chemical Engineering, Vol 24,525-531 